\title{
Left heart failure as the first presentation of primary hyperaldoste- ronism
}

\author{
Ivana Jurin*, \\ Mirjana Kardum Pejić, \\ Vanja Ivanović \\ Mihajlović, \\ Sandra Jakšić \\ Jurinjak, \\ - Irzal Hadžibegović
}

University Hospital Dubrava, Zagreb, Croatia
RECEIVED:

September 9, 2017

ACCEPTED:

September 26, 2017

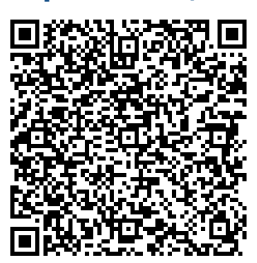

KEYWORDS: heart failure, primary hyperaldosteronism, atrial fibrillation.

CITATION: Cardiol Croat. 2017;12(9-10):354. I https://doi.org/10.15836/ccar2017.354

*ADDRESS FOR CORRESPONDENCE: Ivana Jurin, Klinička bolnica Dubrava, Avenija Gojka Šuška 6, HR-10000 Zagreb, Croatia. / Phone: +385-98-559-387 / E-mail: ivana.sakic@yahoo.com

ORCID: Ivana Jurin http://orcid.org/0000-0002-2637-9691 • Mirjana Kardum Pejić http://orcid.org/0000-0002-6212-3749 Vanja Ivanović Mihajlović http://orcid.org/0000-0001-6931-5404 • Sandra Jakšić Jurinjak http://orcid.org/0000-0002-7349-6137 Irzal Hadžibegović http://orcid.org/0000-0001-9139-5009

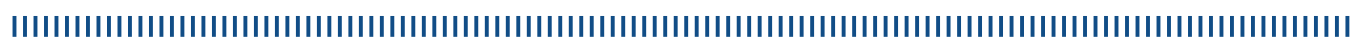

Background: Patients with primary aldosteronism as first described had a low incidence of cardiovascular complications however more recent investigations indicate that long term exposure to elevated aldosterone levels result in a substantial cardiac damage. ${ }^{1}$

Case report: 61-year-old obese male with history of hypertension and paroxysmal atrial fibrillation was admitted to our department because of severe left-dominant heart failure. His heart rhythm was atrial fibrillation and echocardiographic exam revealed dilatation of both left atrium and ventricle with a severe reduction of left ventricular systolic function (EF LV 29\% Simpson) and an abnormal pattern of left ventricular filling. Primary aldosteronism was diagnosed based on severe hypokalemia (2.4 $\mathrm{mEq} / \mathrm{L}$ ) and a low renin-high aldosterone state with hypertension and metabolic alkalosis. Etiology of this condition were expansive masses in right ( $9 \mathrm{~mm}$ in diameter) and in left suprarenal gland (13mm in diameter). Serum potassium was normalized and blood pressure was controlled well by a full dose of an aldosterone receptor blocker (spironolactone $100 \mathrm{mg} /$ day). A diuretic (furosemide) was then added. Rate control of atrial fibrillation was obtained with a beta-adrenergic blocker, and anticoagulation therapy was started. Coronary arteries had no significant stenosis on coronary arteriograms. Twelve days after admission echocardiographic exam was repeated and it showed an excellent improvement in left ventricular systolic function (EF LV 60\% Simpson). Follow up after six months revealed normal potassium levels, well controlled blood pressure and normal systolic function of left ventricle.

Conclusion: We presented a case of a patient with hyperaldosteronism-induced cardiomyopathy. Left ventricular systolic function in primary aldosteronism does not generally differ from other types of hypertensive disease, but here in our case it was clear that elevated aldosterone levels induced systolic heart failure. Nevertheless, in primary aldosteronism abnormal pattern of ventricular filling is commonly detected ${ }^{2,3}$ which contributed to enlargement of left atrial size and atrial fibrillation development in this patient.

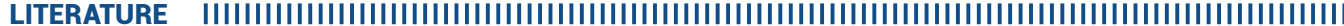

1. Sechi LA, Colussi G, Di Fabio A, Catena C. Cardiovascular and renal damage in primary aldosteronism: outcomes after treatment. Am J Hypertens. 2010 Dec;23(12):1253-60. https://doi.org/10.1038/ajh.2010.169

2. Rossi GP, Di Bello V, Ganzaroli C, Sacchetto A, Cesari M, Bertini A, et al. Excess aldosterone is associated with alterations of myocardial texture in primary aldosteronism. Hypertension. 2002 Jul;40(1):23-7. https://doi.org/10.1161/01.HYP.0000023182.68420.EB

3. Catena C, Colussi G, Di Fabio A, Valeri M, Marzano L, Uzzau A, et al. Mineralocorticoid antagonists treatment versus surgery in primary aldosteronism. Horm Metab Res. 2010 Jun;42(6):440-5. https://doi.org/10.1055/s-0029-1246185 